\title{
APLICATIVOS DE INTERMEDIAÇÃO DE CONTRATOS PRIVADOS DE TRANSPORTE DE PASSAGEIROS: POR QUE A POLÊMICA CONTINUA?
}

\section{Carolina Merida ${ }^{1}$ \\ Renata de Almeida Monteiro ${ }^{2}$}

Resumo: A revolução digital do século XXI disseminou o uso de novas tecnologias ao redor do mundo e, como consequência, a prestação de serviços por meio de aplicativos de celular tornou-se prática corrente no Brasil. Nesse contexto, esta pesquisa tem o escopo de demonstrar a constitucionalidade dos aplicativos de intermediação de contratos de transporte individual de passageiros no país, bem como de discutir alguns equívocos regulatórios quanto à imposição, por diversos municípios brasileiros, de pagamento de preço público por empresas startups do referido segmento. Para tanto, utilizou-se de pesquisa qualitativa, de caráter exploratório, por meio de análise bibliográfica e documental.

Palavras-chave: Aplicativos de transporte; Constitucionalidade; Atividade econômica; Cobrança de preço público; Ilegalidade.

\section{INTERMEDIATION APPS OF PRIVATE PASSENGER TRANSPORT CONTRACTS: WHY IS THE CONTROVERSY CONTINUING?}

\begin{abstract}
The digital revolution of the 21st century disseminated the use of new technologies around the world and, as a consequence, the provision of services through cellular applications became current practice in Brazil. In this context, this research has the scope of demonstrating the constitutionality of the intermediation applications of individual passenger transport contracts in the country, as well as of discussing some regulatory misconceptions regarding the imposition, by various Brazilian municipalities, of payment of public price by startup companies of the segment. For this, it was used of qualitative research, of exploratory character, by means of bibliographical and documentary analysis.
\end{abstract}

Keywords: Transport apps; Constitutionality; Economic activity; Public price collection; Illegality.

\footnotetext{
${ }^{1}$ Doutoranda em Direito Público na UNISINOS, Mestre em Direito, Relações Internacionais e Desenvolvimento pela PUC/GO, Professora Adjunta na Faculdade de Direito da Universidade de Rio Verde (UniRV) e Procuradora do Município de Rio Verde, Goiás. E-mail: carol_merida62@ hotmail.com

${ }^{2}$ Doutoranda em Direito Público na UNISINOS, Mestre em Direito, Relações Internacionais e Desenvolvimento pela PUC/GO, Professora Adjunta na Faculdade de Direito da Universidade de Rio Verde (UniRV) e Advogada. E-mail: monteirorenata@ rocketmail.com
}

Rev. de Direito Administrativo e Gestão Pública | e-ISSN: 2526-0073 | Porto Alegre | v. 4 | n. 2 | p. 99 - 116 | Jul/Dez. 2018 


\section{INTRODUÇÃO}

A sociedade pós-moderna enfrenta constantemente novos desafios, muitos deles decorrentes da revolução tecnológica deflagrada desde o fim do século XX e que se alastra em velocidade e profundidade jamais vistas século XXI adentro.

As novas tecnologias têm sido alvo de resistência por parcela da sociedade, o que vem alimentando discussões tanto em âmbito local como na esfera internacional. A celeuma sobre a proibição ou permissão das atividades executadas pelos aplicativos de intermediação de contratos privados de transporte, objeto de debate nas linhas que se seguem, a par das diversas ações judiciais a que deu causa no Brasil, foi objeto de recente decisão proferida pelo Tribunal da União Europeia ${ }^{3}$.

Nesse contexto, o papel do direito ganha destaque para além da prevenção de riscos, do controle e da regulação das inovações. É necessário que o direito, sobretudo, conduza as inovações para uma direção que conforme os anseios sociais (HOFFMANN-RIEM, 2015), ao mesmo tempo em que respeite o princípio da dignidade da pessoa humana.

Sob outro prisma, a ausência de norma jurídica que regule determinada inovação não pode, por si só, impedir o emprego das novas tecnologias, sob pena de frear o desenvolvimento da sociedade e afrontar os princípios da livre iniciativa, da livre concorrência e da defesa do consumidor.

Muitos serviços intermediados por plataformas eletrônicas, pautados no conceito de economia colaborativa ${ }^{4}$, cujas redes perpassam as fronteiras estatais, a exemplo dos aplicativos de transporte, caíram no gosto dos consumidores e passaram a gerar, ante a ausência de regulação, questionamentos, por parte de seus concorrentes e do Poder Público, acerca de sua clandestinidade, bem como de eventuais riscos aos consumidores.

Situada nesse cenário, a presente pesquisa se propõe a demonstrar a constitucionalidade dos aplicativos de intermediação de contratos privados de transporte individual de passageiros, ao mesmo tempo em que aponta equívocos regulatórios quanto à imposição, por inúmeros municípios brasileiros, de cobrança indevida de preço público das

\footnotetext{
${ }^{3} \mathrm{O}$ objeto e o alcance da aludida decisão serão mencionados no item 3 deste trabalho.

${ }^{4}$ Essas plataformas ou modelos M2L (mercado de dois lados) formam um sistema econômico de redes descentralizadas que combinam bens ou serviços que determinadas pessoas possuem ou possam prestar com as necessidades de outras pessoas, sem a utilização de intermediários.
}

Rev. de Direito Administrativo e Gestão Pública | e-ISSN: 2526-0073 | Porto Alegre | v. 4 | n. 2 | p. 99 - 116 | Jul/Dez. 2018 
empresas startups do referido segmento, as quais, consoante será visto, não se afiguram como delegatárias de serviços públicos.

\section{CONTEXTUALIZAÇÃO DO INÍCIO DE OPERAÇÃO DOS APLICATIVOS DE TRANSPORTE NO BRASIL}

Conforme é cediço, a implementação dos aplicativos de transporte no Brasil se deu em meio a extrema resistência, principalmente por parte de taxistas, que além dos protestos, agiram em todo o mundo com o emprego de violência. Assim nasceu esta nova tecnologia, que não encontrou na legislação brasileira casos semelhantes - as startups chegaram sem precedentes.

Além do americano Uber, primeiro aplicativo de transporte individual e que impulsionou este novo mercado de tecnologia, ainda podem ser mencionados o indiano WillGo, o espanhol Cabify e os brasileiros Televo e OnGo, entre outros.

Cada um deles adota tarifas e cálculos diferentes: o Cabify, por exemplo, não considera o tempo gasto na corrida, enquanto o WillGo não tem bandeirada ${ }^{5}$. E todos os concorrentes do Uber eliminam a tarifa dinâmica, baseada na lei da oferta e da procura, que aumenta os preços em momentos de alta demanda para garantir a disponibilidade de veículos. Os valores das corridas podem variar, a depender de se tratarem de corridas curtas ou longas e, ainda, de corridas com trânsito ou não, tendo em vista que alguns aplicativos cobram pelos minutos parados nos congestionamentos.

De uma maneira geral, todos estes aplicativos cumprem o papel de intermediadores de contratos particulares de transportes ${ }^{6}$. Em síntese, o papel da empresa consiste em filtrar os motoristas colaboradores, impondo alguns requisitos e, em razão do desenvolvimento da tecnologia que é fornecida, cobra uma parte percentual do valor de cada corrida, dependendo do tipo de serviço que seja utilizado.

De outro lado, a regulamentação da atividade dos taxistas pela Administração Pública baseia-se no fornecimento de alvarás de funcionamento e na determinação de tabelas de preços. Contudo, devido à grande demanda por estes alvarás, eles alcançaram valores extremamente altos. Com isto, o preço cobrado por estes serviços subia, sem que a qualidade

\footnotetext{
${ }^{5}$ Trata-se de quantia mínima fixa cobrada pela corrida ou serviço de transporte.

${ }^{6} \mathrm{O}$ item 3 abordará a natureza jurídica dos serviços prestados pelos aplicativos de intermediação de contratos particulares de transporte de forma mais detida.
}

Rev. de Direito Administrativo e Gestão Pública | e-ISSN: 2526-0073 | Porto Alegre | v. 4 | n. 2 | p. 99 - 116 | Jul/Dez. 2018 
na respectiva execução - tais como pontualidade, conforto e limpeza dos veículos, urbanidade dos motoristas-acompanhasse o mesmo escalonamento (RALLO; ROQUE, 2014).

Nessa conjuntura, o advento das atividades das startups gerou resistência dos taxistas, os quais, até então, eram os únicos operando na atividade de transporte individual de passageiros. Um dos principais argumentos defendidos pelos taxistas era o fato de a atividade desempenhada pelos aplicativos ser clandestina em razão da ausência de regulação sobre a nova tecnologia. Entretanto, aludido argumento fora afastado pelos tribunais pátrios, na medida em que as liminares concedidas a favor do funcionamento dos aplicativos de intermediação de transporte individual de passageiros foram mantidas e aquelas concedidas em seu desfavor foram cassadas ${ }^{7}$.

Ademais, não é porque um serviço não é regulamentado, que este seja ilegal, ou clandestino, mesmo porque, quando se trata de novas tecnologias, a inovação sempre chega primeiro, vindo a legislação a reboque.

Após breve contextualização acerca da implantação dos aplicativos de intermediação de transporte de passageiros no Brasil, passa-se à discussão atinente à natureza jurídica de tais serviços.

\section{A NATUREZA JURÍDICA DOS SERVIÇOS PRESTADOS PELOS APLICATIVOS DE TRANSPORTE INDIVIDUAL DE PASSAGEIROS}

Com efeito, desvelar a natureza jurídica de um serviço como o prestado pelo Uber e aplicativos similares é de suma importância para a sua adequada regulação e fiscalização pelo Poder Público.

A esse respeito, destaca-se o disposto nos artigos 730 e 731 do Código Civil Brasileiro $^{8}$, os quais possibilitam tanto a existência de um contrato particular de transporte, quanto a possibilidade do exercício de um contrato de transporte público, que neste caso, seria exercido por meio de autorização, permissão ou concessão, regendo-se por normas regulamentares específicas.

Assim, com o fito de distinguir o serviço privado de transporte dos serviços públicos ou de utilidade pública, é indispensável o exame de tais conceitos na doutrina

\footnotetext{
7 À guisa de exemplo, cita-se a decisão exarada pela desembargadora Márcia Ferreira Alvarenga, da $17^{\mathrm{a}}$ Câmara Cível do Tribunal de Justiça do Rio, que negou agravo de instrumento interposto pelo município do Rio de Janeiro contra decisão de primeira instância favorável ao aplicativo Uber (Agravo de Instrumento 0061837-32.2015.8.19.0000 - TJRJ).

${ }^{8}$ Lei n. ${ }^{\circ} 10.406$, de 10 de janeiro de 2002.
}

Rev. de Direito Administrativo e Gestão Pública | e-ISSN: 2526-0073 | Porto Alegre | v. 4 | n. 2 | p. 99 - 116 | Jul/Dez. 2018 
administrativista brasileira, uma vez que fazem parte das atribuições da Administração Pública. Nesse passo, conforme leciona Meirelles (2011, p. 364):

A atribuição primordial da Administração Pública é oferecer utilidades aos
administrados, não se justificando sua presença senão para prestar serviços à
coletividade. Esses serviços podem ser essenciais ou apenas úteis à comunidade, daí
a necessária distinção entre serviços públicos e serviços de ultilidade pública; mas,
em sentido amplo e genérico, quando aludimos a serviço público, abrangemos
ambas as categorias. (grifo do autor)

Nas duas hipóteses - serviço público e serviço de utilidade pública, há a combinação, em geral, dos mesmos três elementos para a definição, sendo estes elementos: o material, que é o objeto do interesse coletivo, ou seja, as atividades que são de interesse coletivo; o subjetivo, que é a presença do Estado; e o formal, que consiste no procedimento de direito público (DI PIETRO, 2014).

Todavia, há que se salientar que, ante à ausência de definição legal, o conceito de serviço público não é unânime na doutrina. Nesse sentido, Meirelles (2011, p. 366) esclarece os diversos parâmetros levados em consideração pela doutrina para conceituação do 'serviço público' que:

O conceito de serviço público não é uniforme na doutrina, que ora nos oferece uma
noção orgânica, só considerando como tal o que é prestado por órgãos públicos; ora
nos apresenta uma conceituação formal, tendente a identificá-lo por características
extrínsecas; ora nos expõe um conceito material, visando a defini-lo por seu objeto.
Realmente, o conceito de serviço público é variável e flutua ao sabor das
necessidades e contingências políticas, econômicas, sociais e culturais de cada
comunidade, em cada momento histórico, como acentuam os modernos publicistas.
(grifo do autor)

Laubadère (1976, p. 21) apud Carvalho Filho (2015, p. 333) traça um conceito mais simplificado, definindo o serviço público como "toda atividade de uma coletividade pública, visando a satisfazer um objetivo de interesse geral".

Carvalho Filho (2015, p. 333), define que é serviço público "toda atividade prestada pelo Estado ou por seus delegados, basicamente sobre o regime de direito público, com vistas à satisfação de necessidades essenciais e secundárias da coletividade".

Por outro lado, os serviços de utilidade pública, nada mais são que serviços que possuem a sua conveniência para os membros da coletividade, reconhecida pela Administração, de forma que o Estado preste o serviço diretamente ou se preferir indiretamente, por meio das concessões, permissões ou autorizações, controlando a atividade, mas sob conta e risco dos prestadores, mediante remuneração dos usuários, como é o caso dos serviços de transporte coletivo (MEIRELLES, 2011). 
Em correlação com os conceitos administrativistas, é fundamental fazer menção à Lei n. ${ }^{\circ} 12.587 / 2012$, que define as diretrizes da política nacional de mobilidade urbana, único marco legal a diferenciar transporte público individual de passageiros de transporte privado de passageiros quando do início das atividades dos aplicativos de intermediação de transporte de passageiros no Brasil. Contudo, esta Lei não tratava de serviços de intermediação de transporte por aplicativos, consoante se extrai do disposto no artigo $4^{\circ}$, incisos VIII e X do referido diploma legal:

Art. $4^{\circ}$ Para os fins desta Lei, considera-se: [...] VIII - transporte público individual: serviço remunerado de transporte de passageiros aberto ao público, para a realização de viagens individualizadas; [...] $X$ - transporte motorizado privado: meio motorizado de transporte de passageiros utilizado para a realização de viagens individualizadas por intermédio de veículos particulares; (BRASIL, 2012).

Deste modo, afigura-se inviável a aplicação de referida lei às novas startups, vez que nenhuma das situações incluía a intermediação de transporte privado por meio de aplicativo.

Nota-se que o táxi, este sim regulamentado pelo art. $4^{\circ}$, inciso VIII supracitado, por ser um serviço aberto ao público, não pode ser seletivo (ao contrário dos serviços de transporte intermediados por aplicativos).

Em outras palavras, não poderá um taxista recusar qualquer passageiro ou o trajeto por ele solicitado. Já os motoristas cujos serviços são intermediados por aplicativos, sujeitamse aos respectivos regulamentos, inclusive contando com sistema de avaliação dos motoristas pelos usuários e vice-versa, de forma que haja filtro dentre todos, tornando o serviço selecionado e, nisso, diferenciando-o daqueles prestados pelos taxistas 9 .

Portanto, o disposto na Lei n. ${ }^{\circ}$ 12.587/12 não poderia ser aplicado à nova atividade econômica desempenhada pelos aplicativos de intermediação de transporte individual de passageiros. Isso porque, por se tratar de atividade econômica em sentido estrito, só se admite intervenção estatal direta em casos excepcionais, definidos no artigo 173 da Constituição Federal Brasileira, quais sejam, imperativos de segurança nacional ou relevante interesse coletivo.

Desse modo, a atuação estatal, no caso das atividades executadas pelo aplicativo Uber e similares, deve se dar no âmbito da regulação da atividade econômica, que na forma

\footnotetext{
9 Assim entendeu a Secretaria de Acompanhamento Econômico do Ministério da Fazenda, por intermédio da Nota Técnica ${ }^{\circ}$ 06013/2016/DF/COGUN/SEAE/MF, datada em 04 de fevereiro de 2015, quando da análise da representação realizada pela Associação Brasileira das Associações e Cooperativa de Motoristas de Taxi.
}

Rev. de Direito Administrativo e Gestão Pública | e-ISSN: 2526-0073 | Porto Alegre | v. 4 | n. 2 | p. 99 - 116 | Jul/Dez. 2018 
do artigo 174 da Constituição Federal significa exercer as funções de fiscalização, incentivo e planejamento (BRASIL, 1988).

No tocante à natureza jurídica dos serviços executados pelo aplicativo Uber e congêneres, o Tribunal da União Europeia, no final do ano de 2017, se pronunciou no sentido de considerá-los serviços de transporte, uma vez que além de intermediar a relação entre motoristas e passageiros, cria, simultaneamente, uma oferta de serviços de transporte e administra o fluxo dos usuários, sendo a atividade desempenhada pelos aplicativos de transporte essencial para ambos - motoristas e usuários. Assim, o Tribunal afastou a aplicação das diretrizes europeias sobre o comércio eletrônico e abriu espaço para a regulamentação da mencionada atividade pelos países-membros da União Europeia.

\section{PRINCÍPIOS CONSTITUCIONAIS DA LIVRE INICIATIVA E DA LIVRE CONCORRÊNCIA COMO INFORMADORES DA ATIVIDADE ECONÔMICA}

Destarte, tanto o exercício profissional como a execução das atividades econômicas são informados, no Brasil, pelos princípios constitucionais da livre iniciativa e da livre concorrência.

\subsection{Princípio da Livre Iniciativa}

Sarmento (2015) leciona que é extremamente importante tal princípio no ordenamento jurídico, tanto que a Carta Magna o consagrou como um dos fundamentos da República Federativa do Brasil, conforme demonstra o artigo $1^{\circ}$, IV, da Constituição Federal de 1988. Menciona, ainda, a íntima relação do termo "livre inciativa" com a liberdade profissional prevista no artigo $5^{\circ}$, XIII, da Constituição, como um direito fundamental; e, conjuntamente com a valorização do trabalho humano, como um dos fundamentos da ordem econômica nacional, previsto no artigo 170, do diploma constitucional.

O aludido jurista explica: “[...] A livre iniciativa envolve tanto a liberdade de iniciar uma atividade econômica, como de organizá-la, geri-la e conduzi-la”, abarcando para tanto, uma série de componentes constitucionais, como por exemplo, a liberdade de empresa, prevista no parágrafo único do artigo 170, da CF/88; e, a autonomia negocial.

Na mesma linha de raciocínio, Tavares (2015) afirma que o livre exercício de qualquer atividade econômica será ingressado independentemente de qualquer providência de órgãos públicos, ressalvado casos específicos. 
Neste mesmo sentido, Canotilho (2015) ressalta que, além do que prevê o diploma constitucional, a Lei n. ${ }^{\circ}$ 12.965/2014, popularmente conhecida como "Marco Civil da Internet”, também prevê o respeito dos princípios quanto ao uso da internet no Brasil. Dentre estes princípios, encontram-se o da livre iniciativa, o da livre concorrência e o da defesa do consumidor.

Ademais, o inciso VIII do artigo $2^{\circ}$ do supracitado diploma legislativo determina a "liberdade dos modelos de negócios promovidos na internet" como seu fundamento, desde que não haja conflito com demais princípios previstos na Lei n. ${ }^{\circ}$ 12.965/2014.

\title{
4.2. Princípio da Livre Concorrência
}

Considerado também como um dos princípios constitucionais gerais da ordem econômica, previsto no inciso IV, do artigo 170, da Constituição Federal de 1988, o Princípio da Livre Concorrência consiste em uma manifestação da liberdade de iniciativa. Para garantir tal liberdade, a Constituição, em seu artigo $173, \S 4^{\circ}$ defende que será reprimida toda atitude que restar como abuso de poder econômico que vise dominar o mercado, eliminar a concorrência ou até mesmo aumentar os lucros arbitrariamente.

Considerando o exposto, José Afonso da Silva (2005, p. 795), pontua o seguinte:

\begin{abstract}
Os dois dispositivos se complementam no mesmo objetivo. Visam tutelar o sistema de mercado e, especialmente, proteger a livre concorrência, contra a tendência açambarcadora da concentração capitalista. A Constituição reconhece a existência do poder econômico. Este não é, pois, condenado pelo regime constitucional. Não raro esse poder econômico é exercido de maneira anti-social. Cabe, então, ao Estado intervir para coibir o abuso.
\end{abstract}

Outrossim, cabe ressaltar a importância que tem a Lei n. ${ }^{\circ}$ 12.529/2011 (Lei Antitruste e de infrações à ordem econômica) na proteção da livre concorrência.

Nessa senda, Vicente Paulo e Marcelo Alexandrino (2014, p. 997) ressaltam que o Estado não atua somente de forma sancionatória contra os abusos praticados, mas também, age preventivamente no âmbito da função fiscalizadora e regulatória, citando ainda a atuação, das agências reguladoras, em especial o CADE - Conselho Administrativo de Defesa Econômica, tratado na lei mencionada.

Os referidos doutrinadores ainda mencionam outra medida preventiva prevista no artigo 146-A da Constituição Federal, que acrescentado pela Emenda Constitucional 42/2003, prevê a possibilidade de que lei complementar poderá estabelecer critérios especiais de tributação, desde que o objetivo seja para prevenir desequilíbrios. Nesse sentido, Sarmento (2015, p. 11) elucida o caráter dúplice do princípio da livre concorrência: 
O princípio da livre concorrência tem uma dupla face. Por um lado, ele limita o Estado, que não pode instituir restrições excessivas que impeçam os agentes econômicos de ingressar, atuar e competir livremente no mercado. Por outro, o princípio impõe que o Poder Público atue sobre o mercado, para proteger a sua higidez, prevenindo e coibindo abusos do poder econômico e práticas anticoncorrenciais, como a formação de monopólios, oligopólios, cartéis, etc. (grifo do autor)

Portanto, os autores deixam claro que a função do Estado em permitir a livre concorrência e entrada de novas empresas no mercado é essencial para o bom funcionamento da economia.

A análise que se passa a fazer, diz respeito à forma utilizada pelos Municípios para a regulamentação da atividade desempenhada pelos aplicativos de intermediação de transporte individual de passageiros, já que ela passa pela competência legislativa dos entes federativos.

\section{APLICATIVOS DE INTERMEDIAÇÃO DE TRANSPORTE E A COMPETÊNCIA PARA LEGISLAR SOBRE A MATÉRIA}

A Constituição Federal de 1988 procurou manter a mesma linha de raciocínio de outras constituições anteriores, delimitando assim os poderes enumerados da União, poderes remanescentes para os estados e poderes indicativos aos municípios. Procurou ainda distinguir a competência executiva (que neste momento não é relevante) e a competência legislativa, sendo que a capacidade de editar leis pode ser privativa, nos termos do artigo 22, concorrente, conforme demonstra o artigo 24, e suplementar, nos termos do artigo 30, II (MEIRELLES, 2011, p. 375).

Ressalta-se que a Constituição Federal de 1988 em seu artigo 22, I, define que é competência privativa da União legislar sobre direito civil, e outras matérias. Em seguida, no inciso XI, menciona a competência privativa para legislar sobre trânsito e transporte. A peculiaridade aqui, é que o parágrafo único do artigo, permite que Lei Complementar autorize os Estados à legislar sobre matérias previstas no artigo.

Considerando a competência dos municípios, a Constituição Federal de 1988 permite que os mesmos legislem sobre assuntos de interesse local, conforme demonstra o inciso I do artigo 30, bem como em suplementação à União ou aos Estados, no que couber, conforme inciso II.

A Ministra do STJ Nancy Andrighi, em palestra proferida no II Congresso Brasileiro de Internet, organizado pela Abranet e realizado em 24/09/2015, discursou brevemente sobre a questão da competência dos entes em legislar de forma a regulamentar o aplicativo.

Rev. de Direito Administrativo e Gestão Pública | e-ISSN: 2526-0073 | Porto Alegre | v. 4 | n. 2 | p. 99 - 116 | Jul/Dez. 2018 
[...] o artigo 22 da Constituição Federal dispõe que "compete privativamente à União legislar sobre: [...] XI - trânsito e transporte; [...]”. Por outro lado, o artigo 30 prevê que "compete aos municípios: [...] V - organizar e prestar diretamente ou sob regime de concessão ou permissão, os serviços públicos de interesse local, incluído o de transporte coletivo que tem caráter essencial; [...]". Como se percebe, em matéria de transporte, aos Municípios e ao Distrito Federal, por força do parágrafo $1^{\circ}$, do art. 32, da Constituição Federal, competem apenas legislar sobre transporte coletivo, pois, em matéria de transporte individual, como é o Uber, compete privativamente a União legislar, já que aos Estados ainda não há autorização para tanto em razão da inexistência de lei complementar prevista no parágrafo único do art. 22.

A Ministra alertou, ainda, que de acordo com o que trata o inciso I do artigo 22 da Constituição Federal, é a União quem tem privativamente capacidade de legislar sobre direito civil. E, como já demonstrado em outro momento neste trabalho, o Código Civil de 2002 trouxe em seu bojo a previsão do contrato de transporte (artigo 730), promovendo a distinção e peculiaridade do transporte privado individual.

Assim, quando do funcionamento das startups, não havia regramento geral federal que as enquadrasse, afinal, revelaram-se como serviço de transporte privado.

Contudo, mesmo não havendo um regramento geral sobre o assunto, os Poderes Executivos de muitos Municípios, a exemplo de São Paulo e Curitiba, criaram decretos para regulamentação da referida atividade.

Para tanto, fez-se equiparação dos aplicativos de transporte aos serviços de utilidade pública, previstos no artigo 12 da Lei de Mobilidade Urbana, conforme segue:

\footnotetext{
Art. 12. Os serviços de utilidade pública de transporte individual de passageiros deverão ser organizados, disciplinados e fiscalizados pelo poder público municipal, com base nos requisitos mínimos de segurança, de conforto, de higiene, de qualidade dos serviços e de fixação prévia dos valores máximos das tarifas a serem cobradas. (Redação dada pela lei 12.865, de 2013).
}

Todavia, tal equiparação é equivocada, já que se trata de nova tecnologia e, como tal, não encontra parâmetros anteriores à sua existência, ademais de se tratar de transporte privado individual (e, portanto, atividade econômica).

Caso tais serviços fossem de utilidade pública, eles dependeriam de um instrumento público de autorização, permissão ou concessão, o que inviabilizaria o negócio, além do que os municípios não teriam formas de instrumentalizar minimamente, a formalização de tantos instrumentos. 
Portanto, fica claro que estamos diante de decretos sem fundamento legal ${ }^{10}$, pois pretenderam regulamentar uma atividade que não era prevista na Lei n. ${ }^{\circ}$ 12.587/12.

\section{A INCONSTITUCIONALIDADE DE LEIS QUE PROIBIRAM O FUNCIONAMENTO DOS APLICATIVOS}

A par do debate sobre a competência legislativa municipal sobre a matéria, objeto do item anterior, passaremos ao exame dos argumentos relativos à inconstitucionalidade das leis que proibiram o funcionamento dos aplicativos de intermediação de transporte de passageiros.

A esse respeito, a Ministra Nancy Andrighi, como problemática principal de seu discurso no II Congresso Brasileiro de Internet realizado em 24/09/2015, externou a necessidade de tratamento adequado da discussão jurídica quanto à proibição, ou não, dos aplicativos de intermediação de contrato de transporte.

Com efeito, deve-se retomar o teor do artigo $1^{\circ}$, inciso IV, da Constituição Federal de 1988, o qual define a livre iniciativa como um dos fundamentos da República Federativa do Brasil, bem como o disposto no artigo 170 da Lei Fundamental, que dispõe ser a atividade econômica fundada na livre iniciativa e, que dentre outros princípios, deverá respeitar a livre concorrência (inciso IV) e a defesa do consumidor (inciso V).

Ressalta-se, ainda, que claramente o país adotou o capitalismo como modelo de ordem econômica, uma vez que passa ao particular a liberdade de iniciativa e ao mesmo tempo valoriza tanto o trabalho humano quanto a defesa dos consumidores. Logo, é cediço que a maioria das atividades econômicas são exercidas por particulares, podendo o Estado somente exercer tal atividade em casos de imperativos de segurança nacional ou relevante interesse coletivo, conforme demonstra o artigo 173 da Constituição.

Quanto ao poder de legislar sobre a questão, a Ministra acredita que é de competência privativa da União, haja vista que o artigo 22 da Constituição Federal de 1988 prevê esta competência no caso de trânsito e transporte (inciso XI). Correlacionado com este artigo, a Ministra salienta, ainda, o que dispõe o artigo 30 do texto constitucional, que atribui

\footnotetext{
10 No Brasil, o regulamento autônomo ou independente é tratado como exceção, tendo sido inserido na Constituição Federal pela Emenda Constitucional 32/2001, que, ao alterar a redação do artigo 84, inciso VI da Lei Fundamental, estabeleceu dois temas que só podem ser disciplinados por decreto do Presidente da República, quais sejam: organização e funcionamento da administração federal que não implique aumento de despesa, nem criação ou extinção de órgão público; e extinção de funções ou cargos públicos vagos. Desse modo, muito embora a doutrina não seja uníssona, tem-se ao menos essas duas hipóteses de decretos autônomos no direito brasileiro.
}

Rev. de Direito Administrativo e Gestão Pública | e-ISSN: 2526-0073 | Porto Alegre | v. 4 | n. 2 | p. 99 - 116 | Jul/Dez. 2018 
aos municípios, em seu inciso $\mathrm{V}$, a competência para organizar e prestar diretamente ou sob regime de concessão ou permissão, os serviços públicos de interesse local, incluído o de transporte coletivo, que tem caráter essencial.

Em adição, em consonância com o disposto no artigo 22, inciso I da Lei Fundamental, a União possui competência privativa para legislar sobre direito civil. A essa altura, faz-se oportuno relembrar que os artigos 730 e 731 do Código Civil preveem sobre o contrato de transporte e o transporte público.

Ademais, é de relevo para a discussão ora proposta o exame da Lei n. ${ }^{\circ}$ 12.965/2014, conhecida como Marco Civil da Internet, cujo objetivo é estabelecer garantias, direitos e deveres para o uso da internet, enfatizando o teor de seu artigo $2^{\circ}$, inciso $\mathrm{V}$, que prevê como fundamento do uso da internet no Brasil a livre iniciativa, a livre concorrência e a defesa do consumidor, além do fundamento disposto no respectivo artigo $3^{\circ}$, consistente na liberdade dos modelos de negócios providos na internet.

Nesse sentido, Canotilho (2015, p. 28) destaca, ainda, os fundamentos contidos no inciso VI do artigo $2^{\circ}$ do citado diploma legal, que versa sobre a defesa da finalidade social da rede; assim como menciona o disposto no artigo $4^{\circ}$, o qual estabelece que o uso da internet tem como objetivo a promoção do direito de acesso a todos (inciso I), além de buscar a inovação e o fomento à ampla difusão das novas tecnologias e modelos de uso e acesso inciso III).

Por ocasião da conclusão de seu discurso, a Ministra Nancy Andrighi sintetizou o raciocínio até aqui apresentado e opinou pela inconstitucionalidade de leis estaduais, distritais e municipais que porventura proíbam a atividade de intermediação de transporte individual privado de passageiros desempenhada pelo aplicativo Uber e congêneres, conforme segue:

Da conjugação harmônica entre a Constituição Federal, o Código Civil, o Marco Civil da Internet, e a lei 12.529 , não compete aos municípios, aos estados e ao Distrito Federal, legislar sobre aplicativos de internet de intermediação de transporte privado individual, como é o prestado pelos motoristas proprietários de veículos a consumidores que usam tais aplicativos para firmarem entre si este tipo de contrato de transporte, razão pela qual todas as leis municipais, estaduais e distritais que venham a proibir o uso do aplicativo de intermediação para que os consumidores e motoristas proprietários de veículos firmem entre si contratos de transporte privado individual, além de incompatíveis com o artigo 730 e 731 do Código Civil, como Marco Civil da Internet e a Lei 12.529, padecem de grave vício de inconstitucionalidade, por incompatibilidade com o artigo $1^{\circ}, \mathrm{IV}$; artigo 22 , I e XI e $\S$ único; artigo 30, V; artigo 32, $\$ 1^{\circ}$; artigo 170 , IV e V e $\S$ único; e artigo 173 , ambos da Constituição Federal. 
Em adição, o jurista Leonardo Felipe Pimenta de Paoli (2015) pondera que o próprio Código de Defesa do Consumidor já previa: em seu artigo 6º inciso II, "que é direito básico do consumidor ter liberdade de escolha na contratação do serviço ou aquisição do produto. Logo, se ele preferir utilizar a Uber $^{11}$, ao invés de um Táxi, deve ser respeitada a sua escolha" (grifo do autor).

Assim sendo, diante dos princípios e fundamentos constitucionais aqui expostos bem assim do teor da legislação federal trazida ao debate, entende-se que o ato de proibir o funcionamento dos aplicativos que intermediam o serviço de transporte é manifestamente inconstitucional, além de ir de encontro aos anseios dos consumidores, que, por razões das mais variadas, aderiram ao modelo de intermediação de contrato de transporte oferecido pelos aplicativos Uber e similares.

\section{A COBRANÇA INDEVIDA DE PREÇO PÚBLICO DOS APLICATIVOS DE TRANSPORTE}

Antes mesmo da inclusão dos aplicativos de transporte na Lei de Mobilidade Urbana, diversos municípios começaram a legislar sobre a matéria, muitos dos quais para proibir ou restringir as atividades desenvolvidas pelos aplicativos de intermediação de contratos privados de transporte individual de passageiros.

Notadamente quanto à cobrança estatal sobre as atividades executadas pelos referidos aplicativos, passou-se a observar uma voracidade arrecadatória por parte de muitos municípios, que, de algum modo, tentaram se aproveitar da nova tecnologia para aumentar suas receitas. Contudo, isso se deu sem qualquer preocupação com a técnica jurídica.

São exemplos da conduta acima narrada os Municípios de Osasco, Joinville e Goiânia. Entretanto, desde já se alerta para a existência de leis semelhantes adotadas por outras urbes.

O Município de Osasco - SP, por meio dos artigos $12, \S 1^{\circ}$ e 13 , da Lei n. $^{\circ}$ 4.850/2017, estabeleceu a cobrança de $1 \%$, diretamente do aplicativo, do valor pago pelo usuário em cada viagem; valor este que deve ser repassado ao município a título de preço público.

No Município de Joinville - SC, por seu turno, através da Lei n. ${ }^{\circ}$ 8.467/2017, artigo 12, também foi instituído preço público pelo uso intensivo viário urbano, em valores fixados

\footnotetext{
${ }^{11}$ Ou qualquer outro aplicativo de intermediação de contrato de transporte.
} 
pelo Decreto . $^{\circ} 30.272$, de 10 de janeiro de 2018, que variam entre $\mathrm{R} \$ 0,15$ (quinze centavos de real) e R 0,17 (dezessete centavos de real) por quilômetro rodado.

Já em Goiânia - GO, a regulamentação ocorreu por meio do Decreto n. 2.890/2017, que, na mesma linha das cidades já mencionadas, estabeleceu, em seu artigo $7^{\circ}$, parágrafo único, a necessidade de pagamento de $\mathrm{R} \$ 0,10$ (dez centavos de real) por quilometro rodado, à título de preço público pela utilização intensiva da infraestrutura pública viária.

Ocorre que tarifas ou preços públicos somente se justificam quando da existência de delegação de serviço público. Mas, no caso dos aplicativos de transporte, não há delegação como demonstramos a atividade é privada. Malgrado isso, a exação municipal fere, não só a Lei de Mobilidade Urbana, por extrapolar seus limites, mas também a Constituição Federal diretamente, ao desconsiderar a política de tarifas nela traçada.

Constata-se que após a regulamentação dos aplicativos de intermediação de contrato de transporte, tais irregularidades ficaram ainda mais latentes, vez que a Lei n. ${ }^{\circ} 13.640$, de 26 de março de 2018, que alterou a Lei de Mobilidade Urbana, determinou ser cabível aos municípios e ao Distrito Federal: a cobrança dos tributos municipais devidos; a exigência de contratação de seguro de acidentes pessoais a passageiros e do seguro obrigatório (DPVAT); e a exigência de que o motorista esteja inscrito como contribuinte individual no INSS.

Assim, a Lei n. ${ }^{\text {o } 13.640 / 2018 ~ d e l i m i t o u ~ a o s ~ m u n i c i ́ p i o s, ~ o s ~ e x a t o s ~ l i m i t e s, ~ j a ́ ~ t r a c ̧ a d o s ~}$ pela Constituição Federal, mas que vinham sofrendo deturpações, como no caso de regulamentação dos aplicativos de transporte por meio de decreto e cobrança de preço público sem a existência de qualquer contraprestação estatal específica.

Sobre o assunto, há que se invocar o artigo 175 combinado com o artigo 21, inciso XII e alíneas, ambos da Constituição Federal, que estabelecem a possibilidade de o Estado prestar a atividade pública por si mesmo ou, a seu critério, transpassar para terceiros a execução da mesma. No primeiro caso, a cobrança correspondente deve ser uma taxa; enquanto no segundo, sendo a transferência para terceiros por meio de delegação, tratar-se-á de preço público ou tarifa. Nesse último caso, a titularidade continua sendo do Estado, que transfere apenas a tarefa executiva para o terceiro.

Portanto, a incidência de preço público ou tarifa pressupõe a transferência de uma atividade pública a terceiro por meio de concessão, permissão ou autorização (consoante dispõe o artigo 175, parágrafo único, inciso III, da Constituição Federal). Excluem-se desse conceito, por óbvio, os serviços e as obras exercidos pelo setor privado no âmbito da livre iniciativa.

Rev. de Direito Administrativo e Gestão Pública | e-ISSN: 2526-0073 | Porto Alegre | v. 4 | n. 2 | p. 99 - 116 | Jul/Dez. 2018 
No caso dos aplicativos de transporte não há qualquer atividade estatal concedida, permitida ou autorizada, a justificar a cobrança do preço público, o que, por si só, demonstra a ilegitimidade das cobranças relatadas. Destarte, referidas cobranças revelam uma tentativa de participação nos lucros das empresas startups de maneira absolutamente ilegítima.

Desse modo, se a Constituição prevê a existência de tarifas ou preços públicos somente nos casos de delegação, qualquer norma que contrarie diretamente o texto constitucional sob este aspecto estará eivada de inconstitucionalidade.

No caso em debate, aos municípios restariam apenas as seguintes possibilidades de arrecadação: Imposto Sobre Serviços (ISS) ou, ainda, taxas ou preços públicos por uma contraprestação estatal específica, que poderia ser, por exemplo, a atuação pelo poder de polícia $^{12}$.

\section{CONSIDERAÇÕES FINAIS}

Os impactos da revolução digital em curso estão promovendo uma transformação rápida, profunda e complexa na vida em sociedade, alcançando todos os setores econômicos. Caracterizada pelo surgimento de novos modelos de negócio, pela descontinuidade de certas atividades e pela reformulação dos modos de produção, de consumo, de comércio e de trabalho, a mencionada revolução, assim como as inovações dela decorrentes, impõem enormes desafios ao direito.

Para os propósitos da presente pesquisa, coube uma análise mais detida sobre a intermediação dos contratos privados de transporte de passageiros por meio de aplicativos de celular conectados à internet. Nesse sentido, constatou-se que, muito embora tenha havido considerável pressão para a proibição das atividades executadas por tais aplicativos no Brasil, aliás, como em diversos outros países do mundo, a natureza jurídica dos serviços prestados é de direito privado, afigurando-se como atividade econômica, em não como serviço público ou de utilidade pública.

Desse modo, a mera ausência de previsão legal não é razão jurídica suficiente para a proibição dos aplicativos de transporte no país, haja vista que, em virtude de sua natureza, tais atividades de intermediação de contratos privados de transporte de passageiros são informadas pelos princípios da livre iniciativa e da livre concorrência, devendo, quando necessário, ser

\footnotetext{
${ }^{12} \mathrm{Na}$ hipótese de haver, de fato, a aplicação do poder de império da administração pública com o intuito de limitar, condicionar o exercício dos direitos individuais, a liberdade, a propriedade, tudo com o objetivo do bemestar social e do interesse público.
}

Rev. de Direito Administrativo e Gestão Pública | e-ISSN: 2526-0073 | Porto Alegre | v. 4 | n. 2 | p. 99 - 116 | Jul/Dez. 2018 
reguladas e fiscalizadas pelo Poder Público, jamais proibidas, sob pena de flagrante inconstitucionalidade.

Por fim, superada a discussão sobre a inconstitucionalidade da proibição dos aplicativos de transporte no Brasil, verificou-se a existência de equívocos regulatórios por parte de municípios brasileiros, ilustrados pelas legislações de Osasco, Joinville e Goiânia trazidas ao debate, no que diz com a imposição indevida de cobrança às empresas startups do segmento, a título de preço público, sem contraprestação de qualquer atividade pública. Consoante restou sedimentado, referida cobrança revela uma tentativa de participação nos lucros das empresas por parte da Administração Pública Municipal absolutamente ilegítima e que, para além de contrariar os interesses dos consumidores, trata-se de conduta inconstitucional por afronta ao disposto no artigo 175, parágrafo único, inciso III, da Constituição Federal.

\section{REFERÊNCIAS BIBLIOGRÁFICAS}

BRASIL. Constituição (1988). Constituição da República Federativa do Brasil. Brasília, 5 de outubro de 1988. Disponível em: <http://www.planalto.gov.br/ccivil_03/constituicao/ constituicao.htm>. Acesso em: 25 out. 2016.

BRASIL, Ministério da Fazenda - Secretaria de Acompanhamento Econômico. Nota Técnica $\mathbf{n}^{\mathbf{0}}$ 06013/2016/DF/COGUN/SEAE/MF. Brasília: 2016. Disponível em: <http://www.seae.fazenda.gov.br/assuntos/advocacia-da-concorrencia/notas-tecnicas/2016/>. Acesso em: 25/05/2016.

BRASIL, Presidência da República. Lei n. ${ }^{0}$ 10.406, de 10 de janeiro de 2002 . Institui o Código Civil. Disponível em: < http://www.planalto.gov.br/ccivil_03/leis/2002/110406.htm>. Acesso em 02/05/2018.

BRASIL, Presidência da República. Lei $\mathbf{n}^{\circ}$ 12.468, de 26 de agosto de 2011. Regulamenta a profissão de taxista. Disponível em: < http://www.planalto.gov.br/ccivil_03/_Ato20112014/2011/Lei/L12468.htm>. Acesso em 01/05/2016.

BRASIL, Presidência da República. Lei $\mathbf{n}^{\mathbf{0}}$ 12.587, de 3 de janeiro de 2012. Institui as diretrizes da Política Nacional de Mobilidade Urbana; revoga dispositivos dos Decretos-Leis $\mathrm{n}^{\mathrm{os}}$ 3.326, de 3 de junho de 1941, e 5.405, de 13 de abril de 1943, da Consolidação das Leis do Trabalho (CLT), aprovada pelo Decreto-Lei $\mathrm{n}^{-} 5.452$, de $1^{\circ}$ de maio de 1943 , e das Leis $\mathrm{n}^{\mathrm{os}}$ 5.917, de 10 de setembro de 1973, e 6.261, de 14 de novembro de 1975; e dá outras providências. Disponível em: <http://www.planalto.gov.br/ccivil_03/_ato20112014/2012/lei/112587.htm>. Acesso em: 01/05/2018.

BRASIL, Presidência da República. Lei $\mathbf{n}^{\mathbf{0}} \mathbf{1 2 . 9 6 5}$, de 23 de abril de 2014. Estabelece princípios, garantias, direitos e deveres para o uso da Internet no Brasil. Disponível em: <

Rev. de Direito Administrativo e Gestão Pública | e-ISSN: 2526-0073 | Porto Alegre | v. 4 | n. 2 | p. 99 - 116 | Jul/Dez. 2018 
http://www.planalto.gov.br/ccivil_03/_ato2011-2014/2014/lei/112965.htm>. Acesso em: 02/05/2018.

CANOTILHO, José Joaquim Gomes. Parecer. Tema: Situação do Uber no Brasil. Parecer jurídico de 04 de novembro de 2015: Lisboa, Portugal. Disponível em: <http://s.conjur.com.br/dl/parecer-canotilho-uber.pdf>. Acesso em 08/06/2016.

CARVAlHO FILHO, José dos Santos. Manual de Direito Administrativo. 28. ed. - São Paulo: Atlas, 2015.

CDTV, Canal. Palestra - II Congresso Brasileiro de Internet. Realização: Abranet, em 24/09/2015. Palestrante: Ministra do STJ Nancy Andrighi. Vídeo Publicado em: 25 de setembro de 2015. Disponível em: <https://www.youtube.com/watch?v=Zuu_y9cFEZ8>. Acesso em: 24/04/2016.

DI PIETRO, Maria Sylvia Zanella. Direito Administrativo. $27^{\mathrm{a}}$ ed. - São Paulo: Editora Atlas, 2014.

GOIÂNIA, Prefeito Municipal. Decreto n. ${ }^{\circ}$ 2.890, de 6 de outubro de 2017. Estabelece normas para a exploração da atividade econômica de transporte privado individual remunerado de passageiros e o uso intensivo do viário urbano do Município de Goiânia, mediante a utilização de aplicativo de Operadora de Tecnologia. Disponível em: <https://www.goiania.go.gov.br/html/gabinete_civil/sileg/dados/legis/2017/dc_20171006_000 002890.html>. Acesso em: 02/05/2018.

HOFFMANN-RIEM, Wolfgang. Direito, tecnologia e inovação. In: MENDES, Gilmar Ferreira, SARLET, Ingo Wolfgang, COELHO, Alexnadre Zavaglia P. Direito, inovação e tecnologia. São Paulo: Saraiva, 2015, p. 11-32.

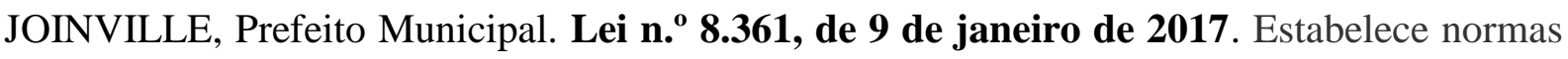
para coibir o transporte clandestino de passageiros no Município de Joinville e dá outras providências. Disponível em: < https://leismunicipais.com.br/a1/sc/j/joinville/leiordinaria/2017/836/8361/lei-ordinaria-n-8361-2017-estabelece-normas-para-coibir-otransporte-clandestino-de-passageiros-no-municipio-de-joinville-e-da-outras-providencias $>$. Acesso em: 02/05/2018.

MEIRELLES, Hely Lopes. Direito Administrativo Brasileiro. $37^{\text {a }}$ ed. - São Paulo: Editora Malheiros, 2011.

OSASCO, Prefeito Municipal. Lei n. ${ }^{\circ}$ 4.850, de 13 de novembro de 2017. Dispõe sobre a regulamentação da prestação do Serviço de Transporte Individual Privado de Passageiros Baseado em Tecnologia de Comunicação em Rede no Município de Osasco e dá outras providências. Disponível em: <https://leismunicipais.com.br/a1/sp/o/osasco/leiordinaria/2017/485/4850/lei-ordinaria-n-4850-2017-dispoe-sobre-a-regulamentacao-daprestacao-do-servico-de-transporte-individual-privado-de-passageiros-baseado-emtecnologia-de-comunicacao-em-rede-no-municipio-de-osasco-e-da-outrasprovidencias? $\mathrm{q}=4850>$. Acesso em: 02/05/2018. 
PAOLI, Leonardo Felipe Pimenta de. A legalidade do Uber. Artigo não paginado. Disponível em: <http://leonardopaoli.jusbrasil.com.br/artigos/217244363/a-legalidade-douber>. Acesso em: 27/04/2016.

PAULO, Vicente; ALEXANDRINO, Marcelo. Direito Constitucional Descomplicado - $13^{\mathrm{a}}$

RALLO, Juan Ramón; ROQUE, Leandro. O cartel dos taxistas contra os aplicativos para carona. Artigo publicado em: 25 de abril de 2014. Não paginado. Disponível em: <http://www.mises.org.br/Article.aspx?id=1848>. Acesso em: 16/05/2016.

SARMENTO, Daniel. Ordem Constitucional Econômica, Liberdade e Transporte Individual de Passageiros: O “caso Uber". Parecer jurídico de 10 de julho de 2015: Rio de Janeiro/RJ. Disponível em: 〈http://s.conjur.com.br/dl/paracer-legalidade-uber.pdf>. Acesso em: 08/06/2016.

SILVA, José Afonso da. Curso de Direito Constitucional Positivo. 25 a ed. - São Paulo: Editora Malheiros, 2005, p.795/796. 